\title{
Some Factors Influencing the Magnitude of the Induced Circular Dichroism of Poly(L-lysine) Hydrobromide and Azo Dye Complexes
}

\author{
Hiroyuki Yamamoto, Ayako Nakazawa, Tadao Hayakawa, \\ and Masaru MITSUISHI* \\ Institute of High Polymer Research and \\ *Department of Industrial Chemistry, \\ Faculty of Textile Science and Technology, \\ Shinshu University, Ueda 386, Japan
}

(Received March 22, 1984)

KEY WORDS Induced CD / Poly(L-lysine)-Dye Complex / Time / Chain
Length / No Interchain Aggregation /

The induced optical activity of dye bound to biopolymers ${ }^{1}$ is a unique characteristic providing information on the electronic transition of the biological systems. The behavior of induced circular dichroism (ICD) of the polypeptide-dye systems reflected the mode of chiral interaction between the polypeptide and dye under a certain environment and was dependent mainly on $\mathrm{pH}$ (conformation) and residue/dye $(\mathrm{R} / \mathrm{D})$ ratio. ${ }^{2,3}$ Several factors including dye structure ${ }^{4}$ and added neutral salts ${ }^{5}$ influenced the shape and magnitude of the ICD spectrum of the system. We have investigated the ICD properties of the poly $(\mathrm{L}-$ lysine) (PLL) $\mathrm{HBr}$-azo dye complexes ${ }^{6,7}$ in some detail, and wish to report the preliminary results on some additional factors which may influence the magnitude of ICD.

The PLL $\mathrm{HBr}$ and poly(D-lysine) (PDL) $\mathrm{HBr}$ samples were synthesized according to the usual $N$-carboxy anhydride method. The degree of polymerization (DP) was determined to be $50,60,240,460,980,1520,1720,3260$, and 4210 for PLL $\mathrm{HBr}$ and 1560 for PDL $\mathrm{HBr}$ from an empirical equation $\log \mathrm{DP}=1.47$ $\log [\eta]+2.99$ in dichloroacetic acid at $25^{\circ} \mathrm{C}$ for $N$-carbobenzoxylated polylysine homologs, ${ }^{8}$ and 20 by $N$-terminal titration in dry dioxane with $1 / 50 \mathrm{~N}$ perchloric acid in glacial acetic acid. ${ }^{9}$ Analogous azo dyes, p-(4-dimethylaminophenylazo)benzenesulfonic acid sodium salt (methyl orange, MO) and $p$-(4-diethylaminophenylazo)benzenesulfonic acid sodium salt (ethyl orange, EO) were guaranteed reagents (Wako), and $p$-(4-di- $n$-propylaminophenylazo)benzenesulfonic acid sodium salt (propyl orange, PO) and $p$-(4-di- $n$-butylaminophenylazo)benzenesulfonic acid sodium salt (butyl orange, BO) were synthesized by the procedure described by Fieser. ${ }^{10}$ The four dyes were purified according to the procedure outlined by Hickinbottom and Lambert ${ }^{11}$ and Klotz et al. ${ }^{12}$ The purity of the dyes was certified by thin layer chromatography. Sample solutions were prepared by adding the dye solutions to the PLL $\mathrm{HBr}$ or PDL $\mathrm{HBr}$ solution. $\mathrm{pH}$ was measured with a Toa Electronics HM-15A digital $\mathrm{pH}$ meter. The final dye concentrations were $2 \times 10^{-5} \mathrm{M}$, and the ratio of $\mathrm{R} / \mathrm{D}$ was 5 . The absorption and $C D$ spectra were measured with a Jasco UVIDEC-1 and a CD J-40A spectrometer, respectively. All the $\mathrm{CD}$ data presented below were reduced to the molar basis of the total 


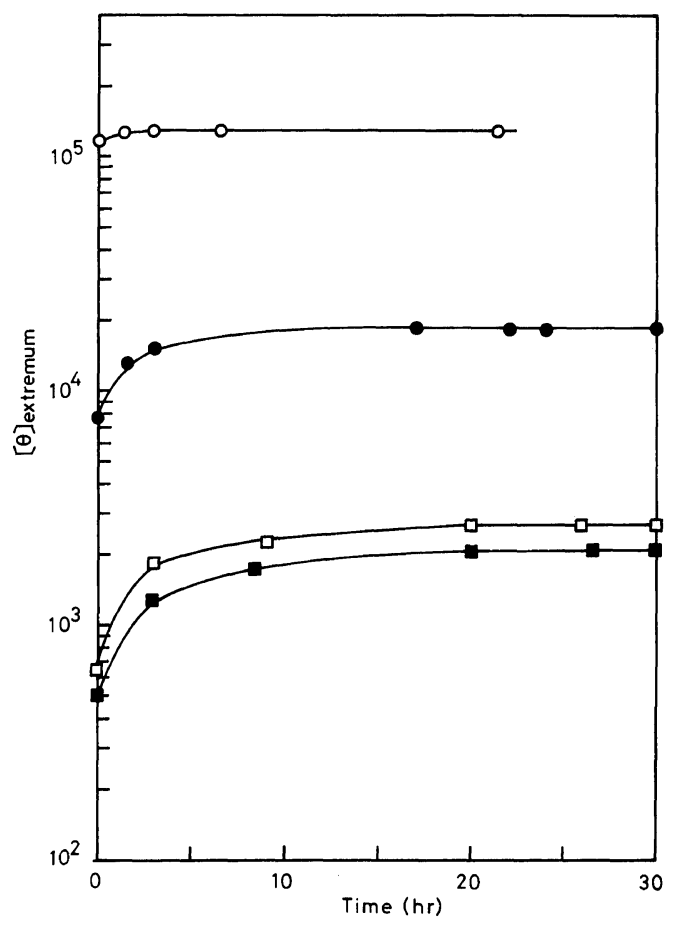

Figure 1. Time dependence of the magnitudes of ICD of the PLL HBr (DP 3260)-azo dye complexes at pH 6 and $R / D=5$ in water $\left(25^{\circ} \mathrm{C}\right): \bigcirc$, MO complex at $359 \mathrm{~nm}$; , EO complex at $371 \mathrm{~nm}$; $\square$, PO complex at $375 \mathrm{~nm}$; 口, BO complex at $395 \mathrm{~nm}$.

dye concentration, and expressed by the ellipticity, $[\theta]$ (degree $\mathrm{cm}^{2} \mathrm{~d} \mathrm{~mol}^{-1}$ ). The $\mathrm{pH}$ and $\mathrm{R} / \mathrm{D}$ dependences of ICD of the PLL-azo dye complexes have been reported previously. ${ }^{6,7}$ Briefly, the random coiled complexes at $\mathrm{pH}$ between 4 and 8 induced $C D$ for the dyes and the $R / D$ ratio of 5 showed the largest ICD values.

The following findings are described in this paper. The ICD spectra of the PLL $\mathrm{HBr}$-dye complexes in water were found to be time dependent on standing without stirring at $\mathrm{pH} 6$ and $R / D=5$. For example, immediately after preparing the mixed solution, the ICD values of the PLL HBr-EO complex were -4600 at $387 \mathrm{~nm}$ and 7600 at $371 \mathrm{~nm}$. After $17 \mathrm{~h}$ at $25^{\circ} \mathrm{C}$, the values increased to -15200 and 18200 , respectively. Figure 1 summarizes the time dependence of the ICD values of the PLL

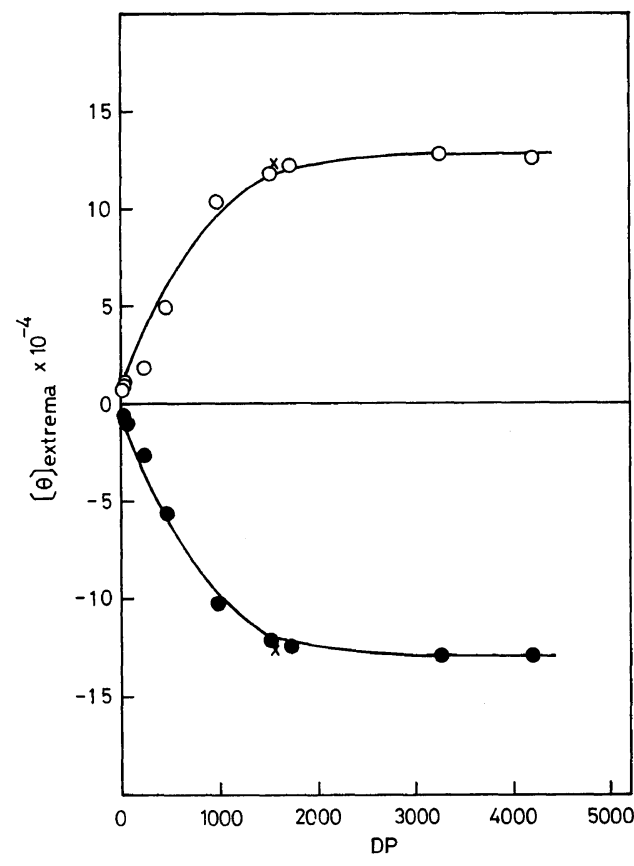

Figure 2. Chain length dependence of the magnitudes of ICD of the PLL HBr-MO complex at $\mathrm{pH} 6$ and $\mathrm{R} / \mathrm{D}=5$ in water $\left(25^{\circ} \mathrm{C}\right): \bigcirc$, at $359 \mathrm{~nm} ; 0$, at $371 \mathrm{~nm}$. Symbol $\times$ denotes the magnitude of the PDL HBr (DP 1560)-MO complex under the same experimental conditions.

$\mathrm{HBr}-\mathrm{azo}$ dye complexes (DP 3260 sample). Final ICD values were $-128000(371 \mathrm{~nm})$ and $129000(359 \mathrm{~nm})$ for the MO complex, -15200 $(387 \mathrm{~nm})$ and $18200(371 \mathrm{~nm})$ for the EO complex, $-2000(430 \mathrm{~nm})$ and $2700(375 \mathrm{~nm})$ for the PO complex, and $-1800(465 \mathrm{~nm})$ and $2100(395 \mathrm{~nm})$ for the BO complex. Next, the MO complex showed the plateau value after $2 \mathrm{~h}$, the EO complex after $17 \mathrm{~h}$, and the PO and BO complexes after $24 \mathrm{~h}$. These suggest that the bulkiness of the $N$-dialkyl moieties in the azo dyes plays an important role in aligning the dye molecules in a nearly parallel orientation along the peptide chain. ${ }^{6,13}$ In this connection, the absorption spectra of the MO and EO complexes showed the blue-shifted peaks at $366 \mathrm{~nm}$ (MO) and $392 \mathrm{~nm}$ (EO), while the $\mathrm{PO}$ and $\mathrm{BO}$ complexes only the shoulders at around $407 \mathrm{~nm}$ (PO) and $410 \mathrm{~nm}$ (BO). 


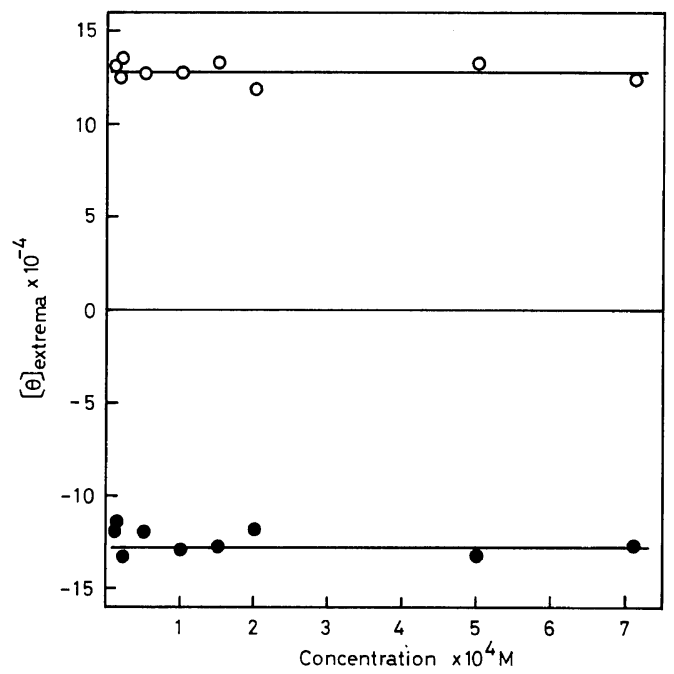

Figure 3. Concentration dependence of the magnitudes of ICD of the PLL HBr (DP 3260)-MO complex at $\mathrm{pH} 6$ and $\mathrm{R} / \mathrm{D}=5\left(25^{\circ} \mathrm{C}\right): \mathrm{O}$, at $359 \mathrm{~nm} ; 0$, at $371 \mathrm{~nm}$. Concentration is based on lysyl residues.

Since the blue-shifted absorption bands result from the interaction between the delocalized $\pi-\pi^{*}$ transition dipoles, the bulkier $N$-dialkyl moieties may disturb the interaction between the transition dipoles and take longer times for the stable complex formation.

Figure 2 shows the chain length dependence of the ICD magnitude of the PLL $\mathrm{HBr}-\mathrm{MO}$ complex in water at $\mathrm{pH} 6$ and $\mathrm{R} / \mathrm{D}=5$. The critical chain length for the ICD magnitude was found to be about DP 1500. The PDL $\mathrm{HBr}$ (DP 1560)-MO complex showed ICD values of 120000 at $371 \mathrm{~nm}$ and -124000 at $359 \mathrm{~nm}$, and was of just the opposite sign to the PLL HBr (DP 1520)-MO complex.
Figure 3 shows the concentration dependence of the extreme values of ICD of the PLL $\mathrm{HBr}$ (DP 3260)-MO complex at $\mathrm{pH} 6$ and $\mathrm{R} / \mathrm{D}=5$. In the concentration range from $10^{-5}$ to $7 \times 10^{-4} \mathrm{M}$ (based on polypeptide residues), the ICD values were not dependent on concentration. This means that no aggregation of the complex occurs. Some additional factors influencing the magnitude of ICD will be reported elsewhere.

\section{REFERENCES}

1. L. Stryer and E. R. Blout, J. Am. Chem. Soc., 83, 1411 (1961).

2. R. E. Ballard, A. J. McCaffery, and S. F. Mason, Biopolymers, 4, 97 (1966).

3. B. C. Myhr and J. G. Foss, Biopolymers, 4, 949 (1966).

4. M. K. Pal and M. Mandel, Biopolymers, 18, 2267 (1979).

5. Y. Sato, M. Hatano, and M. Yoneyama, Bull. Chem. Soc. Jpn., 46, 1980 (1973).

6. M. Hatano, M. Yoneyama, Y. Sato, and Y. Kawamura, Biopolymers, 12, 2423 (1973).

7. H. Yamamoto, A. Nakazawa, and T. Hayakawa, $J$. Polym. Sci., Polym. Lett. Ed., 21, 131 (1983); the PLL hydrochloride sample was used though not described.

8. M. Hatano and M. Yoneyama, J. Am. Chem. Soc., 92, 1392 (1970).

9. M. Sela and A. Berger, J. Am. Chem. Soc., 77, 1893 (1955).

10. L. F. Fieser, "Experiments in Organic Chemistry," D. C. Heath and Company, Boston, 1957, p 191.

11. W. J. Hickinbottom and E. M. Lambert, J. Chem. Soc., 1383 (1939).

12. I. M. Klotz, R. K. Burhard, and J. M. Urquhart, $J$. Am. Chem. Soc., 74, 202 (1952).

13. M. Kasha, H. R. Rawls, and M. A. El-Bayoumi, Pure Appl. Chem., 11, 371 (1965). 